\title{
Determination of Bisphenol A Using a Supramolecule and Photo-CIDNP
}

\author{
Dae Dong Sung, ${ }^{\circ}$ Nak Chang Sung, ${ }^{\dagger}$ Kum Chan Choi, ${ }^{\dagger}$ and Sung Bae Park ${ }^{\ddagger}$ \\ Department of Chemistry and Department of Environmental Engineering, Dong-A Lniversity, Busan 604-71 4, Korea \\ ${ }^{\ddagger}$ Department of Chemistr, Inje Lniversitw, Kimhae 621-749, Korea \\ Received September 19, 2002
}

Key Words : Endocrine disnupter. Supramolecule. Photo-chemically induced polarization (photo-CDNP). Bisphenol A

As a type of endocrine disruptor. bisphenol A $(4,4$ 'isopropy lidenediphenol : BPA) has many harmful effects on the human body. However bisphenol $\mathrm{A}$ is still widely used as a dental treatment agent and in the production of polymers ${ }^{--6}$ Detection methods of small amounts of this compound in environmental samples have been developed by many analytical and environmental scientists. ${ }^{7-9}$ Even with these extensive detection methods. we are still confronted with difficulty on how to make a precise and fast determination of bisphenol A. This report details a new detection method using a supramolecule and compares its effectiveness with that of other methods

\section{Experimental Section}

Apparatus. ${ }^{1} \mathrm{H}$ and ${ }^{13} \mathrm{C}$ NMR spectra were recorded using a Varian Unity Plus 300FT-NMR Spectrometer and a Bruker AC-200 FT-NMR Spectrometer. Mass spectra were recorded using a Micromass Platform II GC/FAB/MS. UV/sis absorption spectra were recorded at $25^{\circ} \mathrm{C}$. using a Shimadzu UV 3101-PC spectrophotometer.

Preparation of Indicator. A type of supramolecule. 4.4'bis(dibenzy lammonium)-bipyridyl-tetrahexafluorophosphate $\left.\left(4-\mathrm{H}_{2}\right)^{4-}\left(4 \mathrm{PF}_{6}\right)^{-4}\right)$ was prepared by Stoddart's method ${ }^{10} \mathrm{~A}$ solution of 4.4 -bipyridine (36 g. $0.23 \mathrm{~mol}$ ) in $2.5 \mathrm{~L}$ of dimethyl sulfoxide was added to a warm solution of $\mathrm{HCl}$ salt (260 g. $0.92 \mathrm{~mol}$ ) of $\mathrm{N}$-benzyl-puri-chloromethylbenzylamine in dimethyl sulfoxide $(2.5 \mathrm{~L})$. The reaction mixture was stirred under reflux for 48 hrs. The reaction progress was detected by using UV/vis absorption spectra. A white precipitate formed and was filtered off after the suspension had been cooled to room temperature. The solid was washed with dimethylformamide and diethỵl ether before being dissolved in water. A saturated aqueous solution of ammonium hexafluorophosphate was added until no further precipitation occurred. The white solid $\left(4-\mathrm{H}^{2}\right)^{4+}\left(4 \mathrm{PF}_{6}\right)^{-4}$ was filtered off and dried. yield: 165 g. $61 \%$. m.p. $240^{\circ} \mathrm{C}$ with decomposition. FAB/MS: $m / z 1013\left[\mathrm{M}-\mathrm{PF}_{6}\right]^{-\cdot}:{ }^{1} \mathrm{H}$ NMR $\left(\mathrm{CD}_{3} \mathrm{COCD}_{3}\right): \delta=4.63$ (s. $\left.4 \mathrm{H}\right), 4.70$ (s. $\left.4 \mathrm{H}\right), 6.21$ (s. $4 \mathrm{H}$ ). $7.40-7.50(\mathrm{~m}, 6 \mathrm{H}) .7 .50-7.60(\mathrm{~m}, 4 \mathrm{H}) .7 .73(\mathrm{~s} .8 \mathrm{H}) .8 .77(\mathrm{~d}$. $4 \mathrm{H}), 9.44(\mathrm{~d}, 4 \mathrm{H})$.

Procedure. Approximately $50 \mu \mathrm{L}$ of acetone- $d_{6}$ were placed into a one $\mathrm{mL}$ serum bottle and the bottle was stoppered with a nubber septum cap. The air in the bottle was purged with argon gas using a micro syringe. One-half milliliter of $\left(4-\mathrm{H}_{2}\right)^{4+}\left(4 \mathrm{PF}_{6}\right)^{-4}$ reagent in acetonitrile- $d_{6}$ was then added to the serum bottle with a micro syringe. The derivative. $\left(4-\mathrm{H}_{2}\right)^{4-}\left(4 \mathrm{PF}_{6}\right)^{-4}$ solution was shaken continually until the sample was completely dissolved in the acetone- $d_{6}$. A $0.1 \mu \mathrm{L}$ aliquot was then pipetted and injected into the probe. as adopted from Wans method. ${ }^{11}$

Detection involved using a technique of photochemically induced magnetic polarization (photo-CIDNP) as shown in Figure 1. Irradiation from the side of the sample probe was perfonmed using a high-intensity UV light beam source. A mixture of the $\left(4-\mathrm{H}_{2}\right)^{4+}$-BPA solution was placed in a quartz cuvette. degassed and sealed. The sample was irradiated in a photo-CIDNP reactor equipped with uncoated low pressure mercury lamp $(254 \mathrm{~nm})$ for $1 \mathrm{lur}$. The formation of the product was observed on an optical bench equipped with a high pressure mercury lamp (Oriel HBO $400 \mathrm{~W}$ in a 7340. lamp housing) and an Oriel high intensity monochromator (Model 7240) with a $5 \mathrm{~nm}$ band pass at $254 \mathrm{~nm}$. The irradiation beam was focused on the sample solution at a critical level: $2.8 \mathrm{~mm}$ above the receiver coil. After irradiation the polarized product. $\left(4-\mathrm{H}_{2}\right)^{4-}$-BPA. was observed inside the receiver coil.

Canned beverage samples were purchased in Busan. South Korea, between March and April 2002. The cans were coated with epoxy over a total area of 2.8 to $3.3 \mathrm{ng} / \mathrm{cm}^{2}$. The concentration was converted into the same ratio of coated

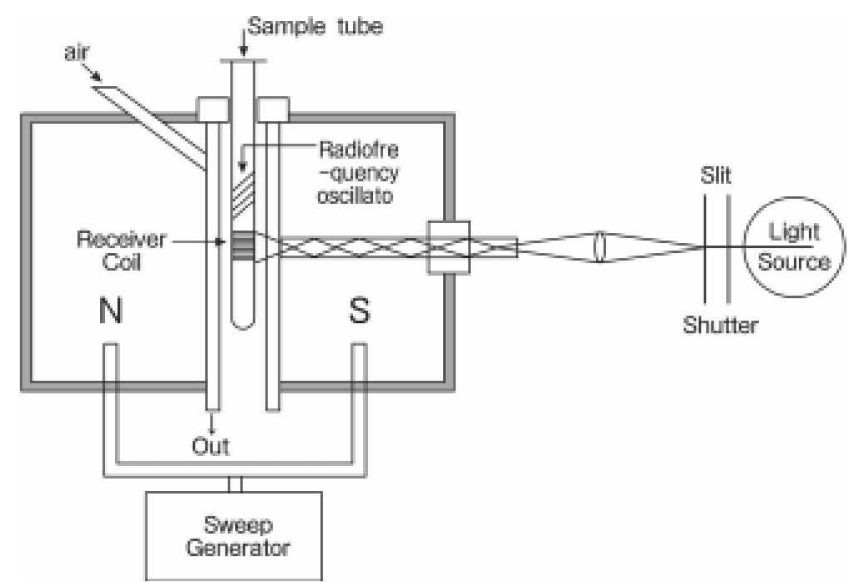

Figure 1. Schematic diagram of the iradiation arrangement in photo CIDNP detection. 


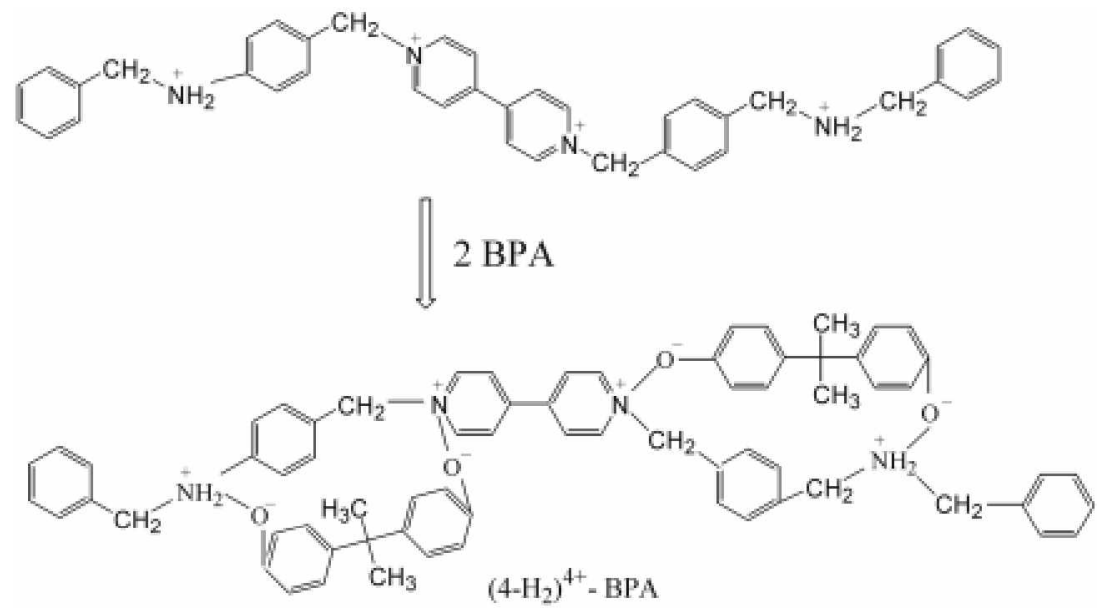

Scheme 1

area after a determination for the same sample. The samples of beverage were concentrated to $7.0-8.0 \%(\mathrm{w} / \mathrm{v})$, using a rotary vacuum evaporator. then they were extracted in chloroform.

\section{Results and Discussion}

In the determination of bisphenol $A$, two phenoxide anions combining with two cation sites of $\left(4-\mathrm{H}_{2}\right)^{4+}\left(4 \mathrm{PF}_{6}\right)^{-4}$ were observed. as shown in Scheme 1. The proton NMR

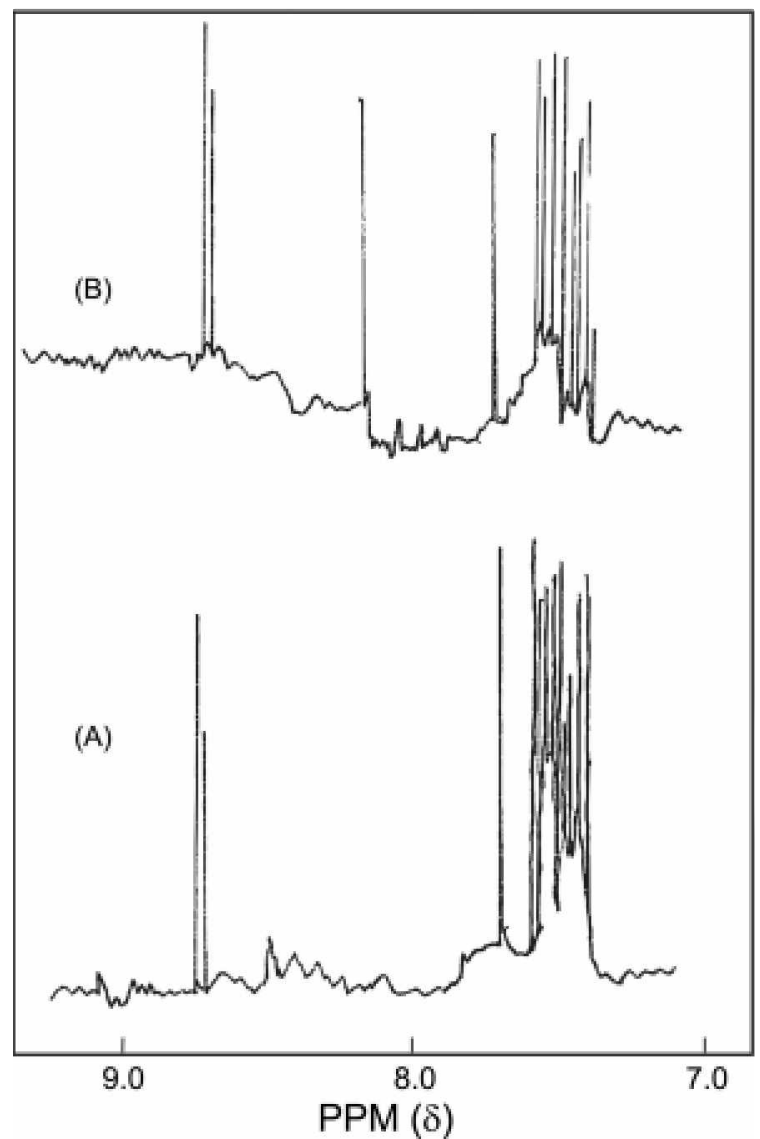

Figure 2. Proton-NMR Spectra recorded $(A)$ betore and $(B)$ atter photo -CIDNP of $4-\mathrm{H}_{2}{ }^{+-}$-BPA. peaks of $\left(4-\mathrm{H}_{2}\right)^{4-}-\left(4 \mathrm{PF}_{6}\right)^{-4}$ are shown in the range of $7.40-$ $7.50 \mathrm{ppm}$ and $7.50-7.60 \mathrm{ppm}$ with multiplets; $7.73 \mathrm{ppm}$ with singlet and 8.77 and $9.44 \mathrm{ppm}$ with doublets. Figure 2 shows the proton-NMR spectra, which were recorded before and after photo-CIDNP. The ${ }^{1} \mathrm{H}-\mathrm{NMR}$ spectra agree with the expected results corresponding to the loss of $\mathrm{PF}_{6}{ }^{-}$and to the binding of 2 moles of BPA. respectively. The intensity of ${ }^{1} \mathrm{H}$ NMR spectra correlated well with the concentrations of BPA. The ${ }^{1} \mathrm{H}-\mathrm{NMR}$ spectrum of $\left(4 \mathrm{H}_{2}\right)^{+4}\left(4 \mathrm{PF}_{6}\right)^{-4}$ was not observed in any other peaks in the region of $7.9-8.6 \mathrm{ppm}(\delta)$. However, a new peak at $8.20 \mathrm{ppm}(\delta)$ appeared soon after the addition of BPA. It is supposed that the new peak corresponds with the product of the binding between pyridinium ions and phenoxide oxygen. The height of the peak is proportional to the concentration of BPA. Figure 3 shows the correlation between the concentration of BPA in the sample solution and the peak intensity in photo-CIDNP. When the concentrations of BPA were changed from $4.98 \times 10^{-8} \mathrm{~g}$ to $32.0 \times 10^{-8} \mathrm{~g}$ the intensities on the ${ }^{1} \mathrm{H}-\mathrm{NMR}$ spectra changed from 0.232 to 2.080 linearly as shown in Figure 2 . This means the photo-CIDNP method is a potentially accurate

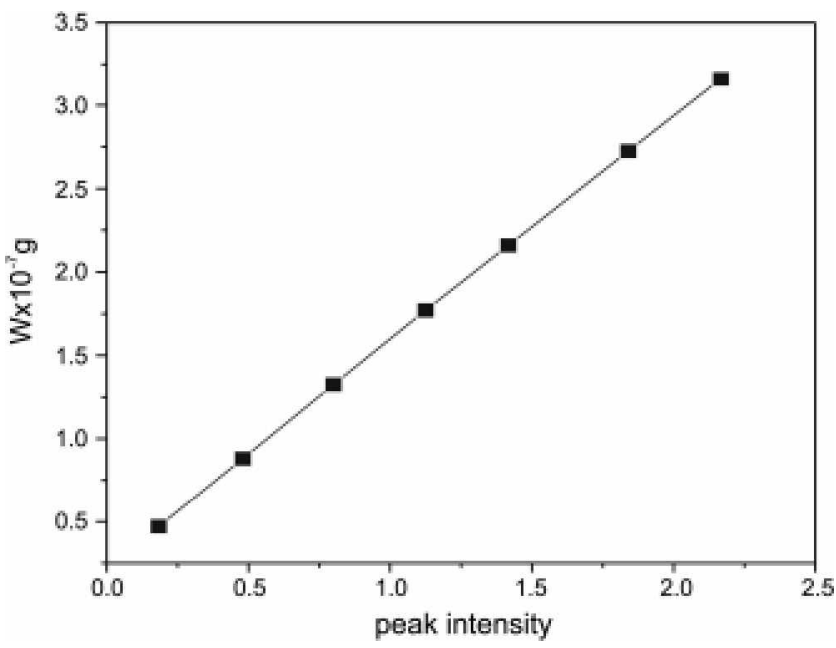

Figure 3. Correlation between the concentration of bisphenol A un solution and the peak intensity in photo-CIDNP. 
Table 1. A Typical Comparison of Bisphenol A Concentrations (ppb) in Canned Beverages

\begin{tabular}{ccc}
\hline Brand & Photo-CIDNP $^{a}$ & Known Method $^{b}$ \\
\hline 1 & 3.8 & 3.7 \\
2 & 4.7 & 4.9 \\
3 & 4.2 & 4.2 \\
4 & 5.7 & 5.8 \\
5 & 8.5 & 8.3 \\
6 & 4.8 & 5.3 \\
7 & 6.4 & 6.9 \\
\hline
\end{tabular}

"detected by using a supramolecule. $\left(4-\mathrm{H}_{2}\right)^{3+}$-BPA. ${ }^{k}$ Detected by using the method of ref. 9 .

way to detect bisphenol $\mathrm{A}$ in the sample. To compare the photo-CIDNP method with the published detection method, ${ }^{9}$ the concentrations of bisphenol $A$ in the same sample solutions were determined using both methods, as shown in Table 1. The concentrations of BPA deternined by photoCIDNP agree with those of the previous known detection method. ${ }^{9}$ even though they show a little bit of deviation in a few beverage samples.

The photo-CIDNP method is potentially more useful to detect bisphenol $\mathrm{A}$ due to the simple preparation of the sample pretreatment and its faster determination compared with the previous known detection methods. ${ }^{7 \cdot 9}$ which require a solid phase extraction. concentration. determination, and funally confirmation using the combined tecluniques of $\mathrm{GC}$. HPLC and GC/MS.

In summary, we have established a new determination method of bisphenol A, using a supramolecule and an application technique of photochemically induced magnetic polarization (photo-CIDNP). The probe intensities of photoCIDNP are correlated linearly with the concentrations of bisphenol $\mathrm{A}$ in the spiked and canned beverage samples.
This determination is simple and fast compared with other reported methods. The photo-CIDNP method is shown to be a superior procedure to detect bisphenol A in environmental samples.

Acknowlegment. We thank Dong-A University for financial support. The acquisition of the $300 \mathrm{MHz}$ FT-NMR Spectrometer and $200 \mathrm{MHz}$ FT-NMR Spectrometer was supported by the Korea Basic Science Institute. Busan Branch and the Research Facility Center. Dong-A University. We are indebted to Dr. Sang Hoon Lee, the Institute of Health and Emironment. Busan Metropolitan City for providing beverage samples and bisphenol $\mathrm{A}$.

\section{References}

1. Ben-Ionlathan. N.: Cooper. R. L.: Foster. P.: Hughes. C. L.: Hoyer. P. B.: Klotz. D.; Kolm, M.: Lamb. D. J.; Stancel. G. M. Enniromental Health Prorspectives 1999. 107,605.

2. Jocelyn. K. Science 1996, 274. $1837 \mathrm{~b}$.

3. Science 1998. 280.2053.

4. Science 1998. $281.1425 \mathrm{c}$.

5. Science 2000. 287.543d.

6. Jansen. US. Pot. 2 1948, 468,982 . The Merk Index, $10^{\text {th }}$ ed.. 1299. Merk \& Co. INC. Rahway, N.J. U.S.A. 1983.

7. Takao, Y.; Lee, H. C.: Ishibashi, Y.; Kohra. S.; Tominaga, N.: Arizono. K. Proceedings of the $24^{\text {th }}$ Symposium on Toxicology and Emiromental Health. Osaka. Japan. October. 29-30. 1998.

8. Brydia. L. E. Analyt. Chem. 1968. 2212.

9. Biles. J. E.: MoNeal, T. P.: Begley. T. H. J. Agric. Food Chent 1997. 45,4697 .

10. Ashton. P. R.: Glink. P. T.: M.-Diaz, M.-V; Stoddart, F.: White A J. P.: Williams. D. J. Angew: Chem. Int Ed. Engl. 1996. 35(17). 1930 .

11. Wan. J. K. S. "Theory and Application of Chemical Induced Magretic Polarization in Photochemistr" in "Adtances in Photochemisny, Pitts, J. N. Jr. Ed.. Interscience. John Wiley: New York, 1980; Vol. 12, p 315 